\title{
Classification of acute myeloid leukemia
}

\author{
Sang Mee Hwang \\ Department of Laboratory Medicine, Seoul National University Bundang Hospital, Seongnam, Korea
}

p-ISSN 2287-979X / e-ISSN 2288-0011

https://doi.org/10.5045/br.2020.S001

Blood Res 2020;55:S1-S4.

Received on November 14, 2019

Revised on January 23, 2020

Accepted on January 31, 2020

\section{Correspondence to}

Sang Mee Hwang, M.D.

Department of Laboratory Medicine, Seoul

National University Bundang Hospital, 82

Gumi-ro 173 beon-gil, Bundang-gu,

Seongnam 13620, Korea

E-mail: smilemee@snubh.org

(C) 2020 Korean Society of Hematology

\begin{abstract}
The World Health Organization (WHO) Classification of Tumors of Hematopoietic and Lymphoid Tissues was revised in 2017 on the basis of recent high-throughput sequencing and gene expression data on hematologic malignancies. This review explores the current WHO classification of acute myeloid leukemia (AML) and related precursor neoplasms, highlighting the changes made in the current edition and focusing on the diagnosis of AML.
\end{abstract}

Key Words Acute myeloid leukemia, Classification, Diagnosis

\section{INTRODUCTION}

Acute myeloid leukemia (AML) comprises a heterogeneous group of neoplastic disorders in which $\geq 20 \%$ of cells in the blood or bone marrow are myeloblasts. Historically, AML has been classified according to the morphology and immunophenotype but since the 3rd edition of the World Health Organization (WHO) Classification of Tumors of Hematopoietic and Lymphoid Tissues, genetic abnormalities have been incorporated in the diagnostic algorithms for AML $[1,2]$. Recurrent genetic abnormalities include chromosomal translocations involving transcription factors associated with distinct clinical, morphological, and immunophenotypic features that define a clinicopathological and genetic entity. In the revised 4th edition of the WHO classification published in 2017 [3], AML is classified into 6 categories: AML with recurrent genetic abnormalities; AML with myelodysplasia-related changes (MRC); therapy-related myeloid neoplasms (t-MN); AML, not otherwise specified (NOS); myeloid sarcoma; and myeloid proliferations related to Down syndrome (DS) (Table 1). This review discusses each of these categories and highlights the initial diagnostic workup necessary for their diagnosis.

AML with recurrent genetic abnormalities

This entity includes AML with balanced translocation/ inversions, as well as AML with gene mutations, and accounts for about $20-30 \%$ of patients with AML. AML with balanced translocations include $\mathrm{t}(8 ; 21)(\mathrm{q} 22 ; \mathrm{q} 22.1) ; R U N X 1-R U N X 1 T 1$, $\operatorname{inv}(16)(\mathrm{p} 13.1 \mathrm{q} 22)$ or $\mathrm{t}(16 ; 16)(\mathrm{p} 13.1 ; \mathrm{q} 22) ; \quad C B F B-M Y H 11$, $P M L-R A R A, \mathrm{t}(9 ; 11)(\mathrm{p} 21.3 ; \mathrm{q} 23.3) ; \quad K M T 2 A-M L L T 3, \mathrm{t}(6 ; 9)$ (p23;q34.1); DEK-NUP214; inv(3)(q21.3q26.2) or t(3;3)(q21.3; $\mathrm{q} 26.2) ; \quad G A T A 2, \quad M E C O M, \mathrm{t}(1 ; 22)(\mathrm{p} 13.3 ; \mathrm{q} 13.1) ; \quad R B M 15$ $M K L 1$; and (provisional entity) AML with $B C R-A B L 1$. Many of these disease categories have characteristic morphological and immunophenotypic features. Of these categories, if $P M L-R A R A$ and $\operatorname{inv}(16)(\mathrm{p} 13.1 \mathrm{q} 22)$ or $\mathrm{t}(16 ; 16)$ are present with $\mathrm{t}(8 ; 21)$, AML can be diagnosed regardless of the blast count [3]. AML with $B C R-A B L 1$ is a newly introduced provisional entity that was included separately despite low incidence because its characteristics are different from the blast phase of chronic myeloid leukemia [4] and is an aggressive disease. Moreover, studies have shown that patients with this form of AML might benefit from tyrosine kinase therapy $[5,6]$.

AML with gene mutations is another category under AML with recurrent genetic abnormalities. AML with mutated NPM1 and biallelic CEBPA have been incorporated into the "AML with recurrent genetic abnormalities" entity, and AML with RUNX1 mutation was added as a new provisional entity. AML with NPM1 mutation is the most recurrent genetic mutation in AML and is usually associated with a normal karyotype [7]. NPM1-mutated AML shows good 
Table 1. World Health Organization (WHO) classification of myeloid neoplasms and acute leukemia.

WHO classification of myeloid neoplasms and acute leukemia

Acute myeloid leukemia (AML) and related neoplasms

AML with recurrent genetic abnormalities

AML with $\mathrm{t}(8 ; 21)(\mathrm{q} 22 \mathrm{q} 22.1) ; R U N X 1-R U N X 1 T 1$

AML with inv(16)(p13.1q22) or $\mathrm{t}(16 ; 16)(\mathrm{p} 13.1 ; \mathrm{q} 22)$;

$$
\text { CBFB-MYH11 }
$$

APL with PML-RARA

AML with $\mathrm{t}(9 ; 11)(\mathrm{p} 21.3 ; \mathrm{q} 23.3) ; K M T 2 A-M L L T 3$

AML with $\mathrm{t}(6 ; 9)(\mathrm{p} 23 ; \mathrm{q} 34.1) ; D E K-N U P 214$

AML with inv(3)(q21.3q26.2) or t(3;3)(q21.3; q26.2); GATA2, MECOM

AML (megakaryoblastic) with $\mathrm{t}(1 ; 22)(\mathrm{p} 13.3 ; \mathrm{q} 13.1)$; RBM15-MKL1

Provisional entity. AML with BCR-ABL1

AML with mutated NPM1

AML with biallelic mutation of CEBPA

Provisional entity: AML with mutated RUNX1

AML with myelodysplasia-related changes

Therapy-related myeloid neoplasms

AML, not otherwise specified (NOS)

AML with minimal differentiation

AML without maturation

AML with maturation

Acute myelomonocytic leukemia

Acute monoblastic and monocytic leukemia

Pure erythroid leukemia

Acute megakaryoblastic leukemia

Acute basophilic leukemia

Acute panmyelosis with myelofibrosis

Myeloid sarcoma

Myeloid proliferations associated with Down syndrome

Transient abnormal myelopoiesis (TAM) associated with

Down syndrome

Myeloid leukemia associated with Down syndrome

prognosis, but accompanying FLT3-ITD mutations may alter the prognosis $[8,9]$. In the revised classification, only those with biallelic CEBPA mutation are included as a separate entity owing to its beneficial effect on prognosis $[10,11]$. AML with mutated RUNX1 has been incorporated in to the AML classification and is known to have poor prognosis $[12,13]$. However, a diagnosis of RUNX1-mutated AML should not be made for cases that fulfil the criteria for other specific AML subtypes, including AML-MRC, $\mathrm{t}-\mathrm{MN}$, or AML with recurrent genetic abnormalities. Most RUNX1 mutations are monoallelic, and the mutations are commonly frameshift or missense without any hotspots [14]. Although AML with FLT3 mutations are frequently present, it is not separately assigned as an entity due to its presence in many AML subtypes. Nevertheless, owing to their therapeutic [15] and prognostic significance [16], testing for FLT3 mutations must be carried out in all patients with AML $[8,9]$.

\section{AML with myelodysplasia related changes}

The diagnosis of AML-MRC requires that the following
Table 2. Cytogenetic abnormalities diagnostic of acute myeloid leukemia with myelodysplasia-related changes [3].

\begin{tabular}{ll}
\hline Type of cytogenetic abnormality & \multicolumn{1}{c}{ Karyotype } \\
\hline Complex karyotype & 3 or more abnormalities \\
Unbalanced abnormalities & $-7 / \operatorname{del}(7 \mathrm{q})$ \\
& $\operatorname{del}(5 \mathrm{q}) / \mathrm{t}(5 \mathrm{q})$ \\
$\mathrm{i}(17 \mathrm{q}) / \mathrm{t}(17 \mathrm{p})$ \\
$-13 / \mathrm{del}(13 \mathrm{q})$ \\
$\mathrm{del}(11 \mathrm{q})$ \\
$\mathrm{del}(12 \mathrm{p}) / \mathrm{t}(12 \mathrm{p})$ \\
$\mathrm{idic}(\mathrm{X})(\mathrm{q} 13)$ \\
$\mathrm{t}(11 ; 16)(\mathrm{q} 23.3 ; \mathrm{p} 13.3)$ \\
$\mathrm{t}(3 ; 21)(\mathrm{q} 26.2 ; \mathrm{q} 22.1)$ \\
$\mathrm{t}(1 ; 3)(\mathrm{p} 36.3 ; \mathrm{q} 21.2)$ \\
$\mathrm{t}(2 ; 11)(\mathrm{p} 21 ; \mathrm{q} 23.3)$ \\
$\mathrm{t}(5 ; 12)(\mathrm{q} 32 ; \mathrm{p} 13.2)$ \\
$\mathrm{t}(5 ; 7)(\mathrm{q} 32 ; \mathrm{q} 11.2)$ \\
$\mathrm{t}(5 ; 17)(\mathrm{q} 32 ; \mathrm{p} 13.2)$ \\
$\mathrm{t}(5 ; 10)(\mathrm{q} 32 ; \mathrm{q} 21)$ \\
$\mathrm{t}(3 ; 5)(\mathrm{q} 25.3 ; \mathrm{q} 35.1)$ \\
\end{tabular}

criteria are met. First, the blast count in blood or marrow should be $\geq 20 \%$; second, patients should have a history of myelodysplastic syndrome (MDS) or MDS/myeloproliferative neoplasm (MPN), or MDS-related cytogenetic abnormality (Table 2) or multilineage dysplasia; and third, patients should not have received prior cytotoxic or radiation therapy for an unrelated disease or have the recurrent cytogenetic abnormalities described for AML with recurrent genetic abnormalities. AML-MRC generally has a poor prognosis with a lower rate of complete remission than other AML subtypes $[17,18]$. To diagnose AML-MRC based on morphology, dysplasia must be present in $\geq 50 \%$ of cells in at least two hematopoietic cell lines. Moreover, multilineage dysplasia alone is insufficient to diagnose AML-MRC in a de novo case of AML with mutated NPM1 or biallelic mutations of $C E B P A$, as the prognosis is not different regardless of the presence of multilineage dysplasia in these subtypes $[19$, 20]. Deletion $(9 q)$ has been removed from the MDS-related cytogenetic abnormalities that are now used to define AML-MRC owing to the association with $N P M 1$ or biallelic CEBPA mutations [21, 22].

\section{Therapy-related myeloid neoplasm}

$\mathrm{t}$-MN includes $\mathrm{t}-\mathrm{AML}, \mathrm{t}$-MDS, $\mathrm{t}-\mathrm{MDS} / \mathrm{MPN}$, which occur as a complication of cytotoxic therapy and/or radiation therapy administered for a prior neoplastic or non-neoplastic disorder. Cytotoxic agents implicated in t-MN include alkylating agents, topoisomerase II inhibitors, some antimetabolites, anti-tubulin agents, and radiation therapy. t-MN accounts for $10-20 \%$ of all cases of MDS and AML [23]. Regardless of the blast count and morphologic diagnosis, $\mathrm{t}-\mathrm{MDS}$ and $\mathrm{t}-\mathrm{AML}$ are included as $\mathrm{t}-\mathrm{MN}$, owing to the presence of prior iatrogenic exposure to mutagenic agents and its relation to pathogenesis of the $\mathrm{t}-\mathrm{MN}$, although recent studies have suggested some inherited risk factors [24, 25]. The prognosis of $\mathrm{t}-\mathrm{MN}$ is generally poor, influenced by cyto- 
genetic and genetic mutations, as well as the underlying malignancy for which prior therapy was received [26, 27].

\section{Acute myeloid leukemia, not otherwise specified}

Cases of AML that are not classified into any of the abovementioned categories are classified as AML, NOS. This category classifies AML based on morphology, cytochemistry, and immunophenotype, which was the basis for earlier AML classifications $[1,2]$. Subcategories include AML with minimal differentiation, without maturation, with maturation, acute myelomonocytic leukemia, acute monoblastic and monocytic leukemia, pure erythroid leukemia, acute megakaryoblastic leukemia, acute basophilic leukemia, and acute panmyelosis with myelofibrosis. Changes have been made for erythroid leukemia and bone marrow with $>80 \%$ immature erythroid precursors; bone marrow nucleated cells with $>30 \%$ proerythroblasts is only included in the pure erythroid leukemia category and thus, the myeloblast counts are $<20 \%$ [28]. Cases previously classified as erythroleukemia (myeloid/erythroid) are now classified as MDS according to the blast count, cytopenia, and dysplasia, because they share greater similarity with MDS than with AML [29, 30].

\section{Myeloid sarcoma}

A tumor mass consisting of myeloid blasts, occurring at a site other than the bone marrow, is diagnosed as myeloid sarcoma. The diagnosis is equivalent to a diagnosis of AML and can precede or coincide with AML [31, 32]. Myeloid sarcoma shows blastic-type as well as monoblastic or myelomonocytic type [31]; recent studies using next-generation sequencing have identified mutations similar to those implicated in AML, such as KIT or FLT3 mutations [33].

\section{Myeloid proliferations associated with Down syndrome}

Individuals with DS are known to have increased risk of leukemia [34, 35]. Transient abnormal myelopoiesis (TAM) associated with DS and myeloid leukemia associated with DS are included in this category. TAM is a disorder of newborns with DS that presents with clinical and morphological findings of AML at 3-7 days after birth [36]. Most patients exhibit spontaneous remission but others develop AML after 1-3 years. Most cases of myeloid leukemia associated with DS are acute megakaryoblastic leukemia [37]. In individuals with DS, the distinction between MDS and AML is irrelevant; thus, both are included in the category of myeloid leukemia associated with DS. In addition to trisomy 21, mutations of GATA1 are pathognomonic of this category [38]. These children should be treated based on DS-specific protocols [39].

\section{CONCLUSION}

Diagnosis of AML according to the revised WHO classification [3] requires the results of morphological, immunophenotypic, cytogenetic, and molecular genetic testing, as well as prior medical history and clinical information. For adult patients with AML, cytogenetic and molecular genetic testing results are needed to assign AML to the recurrent genetic abnormalities category. Cytogenetic studies, screening for gene rearrangements, and assessment of gene panels including $N P M 1, C E B P A, R U N X 1$ are currently required for classification. The medical history or prior therapy history is necessary to assign AML to t-MN or AML-MRC. If patients are not assigned to any one of these prior categories, a diagnosis of AML, NOS is made based on the morphology and immunophenotype. In individuals with DS, myeloid proliferations related to DS should be considered. Recent molecular genetic findings will further enrich our understanding of AML and are expected to be incorporated into future classifications.

\section{Authors' Disclosures of Potential Conflicts of Interest}

No potential conflicts of interest relevant to this article were reported.

\section{REFERENCES}

1. Arber DA, Brunning RD, Le Beau MM, et al. Acute myeloid leukaemia (AML) and related precursor neoplasms. In: Swerdlow SH, Campo E, Harris NL, et al, eds. WHO classification of tumours of haematopoietic and lymphoid tissues. 4th ed. Lyon, France: IARC Press, 2008:110-44.

2. Jaffe ES, Harris NL, Stein H, Vardiman JW. Pathology and genetics of tumours of haematopoietic and lymphoid tissues. 3rd ed. Lyon, France: IARC Press, 2001:75-105.

3. Arber DA, Brunning RD, Le Beau MM, et al. Acute myeloid leukaemia and related precursor neoplasms. In: Swerdlow SH, Campo E, Harris NL, et al, eds. WHO classification of tumours of haematopoietic and lymphoid tissues. Revised 4th ed. Lyon, France: IARC Press, 2017:130-71.

4. Neuendorff NR, Burmeister T, Dörken B, Westermann J. BCR-ABL-positive acute myeloid leukemia: a new entity? Analysis of clinical and molecular features. Ann Hematol 2016; 95:1211-21.

5. Soupir CP, Vergilio JA, Dal Cin P, et al. Philadelphia chromosomepositive acute myeloid leukemia: a rare aggressive leukemia with clinicopathologic features distinct from chronic myeloid leukemia in myeloid blast crisis. Am J Clin Pathol 2007;127: 642-50.

6. Konoplev S, Yin CC, Kornblau SM, et al. Molecular characterization of de novo Philadelphia chromosome-positive acute myeloid leukemia. Leuk Lymphoma 2013;54:138-44.

7. Papaemmanuil E, Gerstung M, Bullinger L, et al. Genomic classification and prognosis in acute myeloid leukemia. N Engl J Med 2016;374:2209-21.

8. Tallman MS, Wang ES, Altman JK, et al. Acute myeloid leukemia, Version 3.2019, NCCN Clinical Practice Guidelines in Oncology. J Natl Compr Canc Netw 2019;17:721-49.

9. Döhner H, Estey E, Grimwade D, et al. Diagnosis and management 
of AML in adults: 2017 ELN recommendations from an international expert panel. Blood 2017;129:424-47.

10. Dufour A, Schneider F, Metzeler KH, et al. Acute myeloid leukemia with biallelic CEBPA gene mutations and normal karyotype represents a distinct genetic entity associated with a favorable clinical outcome. J Clin Oncol 2010;28:570-7.

11. Wouters BJ, Löwenberg B, Erpelinck-Verschueren CA, van Putten WL, Valk PJ, Delwel R. Double CEBPA mutations, but not single CEBPA mutations, define a subgroup of acute myeloid leukemia with a distinctive gene expression profile that is uniquely associated with a favorable outcome. Blood 2009;113: 3088-91.

12. Gaidzik VI, Teleanu V, Papaemmanuil E, et al. RUNX1 mutations in acute myeloid leukemia are associated with distinct clinicopathologic and genetic features. Leukemia 2016;30:2160-8.

13. Stengel A, Kern W, Meggendorfer M, et al. Number of RUNX1 mutations, wild-type allele loss and additional mutations impact on prognosis in adult RUNX1-mutated AML. Leukemia 2018; 32:295-302.

14. Schnittger S, Dicker F, Kern W, et al. RUNX1 mutations are frequent in de novo AML with noncomplex karyotype and confer an unfavorable prognosis. Blood 2011;117:2348-57.

15. Daver N, Schlenk RF, Russell NH, Levis MJ. Targeting FLT3 mutations in AML: review of current knowledge and evidence. Leukemia 2019;33:299-312.

16. Kottaridis PD, Gale RE, Frew ME, et al. The presence of a FLT3 internal tandem duplication in patients with acute myeloid leukemia (AML) adds important prognostic information to cytogenetic risk group and response to the first cycle of chemotherapy: analysis of 854 patients from the United Kingdom Medical Research Council AML 10 and 12 trials. Blood 2001; 98:1752-9.

17. Arber DA, Stein AS, Carter NH, Ikle D, Forman SJ, Slovak ML. Prognostic impact of acute myeloid leukemia classification: importance of detection of recurring cytogenetic abnormalities and multilineage dysplasia on survival. Am J Clin Pathol 2003; 119:672-80.

18. Gahn B, Haase D, Unterhalt M, et al. De novo AML with dysplastic hematopoiesis: cytogenetic and prognostic significance. Leukemia 1996;10:946-51.

19. Bacher U, Schnittger S, Macijewski K, et al. Multilineage dysplasia does not influence prognosis in CEBPA-mutated AML, supporting the WHO proposal to classify these patients as a unique entity. Blood 2012;119:4719-22.

20. Falini B, Macijewski K, Weiss T, et al. Multilineage dysplasia has no impact on biologic, clinicopathologic, and prognostic features of AML with mutated nucleophosmin (NPM1). Blood 2010;115: 3776-86.

21. Haferlach C, Mecucci C, Schnittger S, et al. AML with mutated NPM1 carrying a normal or aberrant karyotype show overlapping biologic, pathologic, immunophenotypic, and prognostic features. Blood 2009;114:3024-32.

22. Schlenk RF, Taskesen E, van Norden $Y$, et al. The value of allogeneic and autologous hematopoietic stem cell transplantation in prognostically favorable acute myeloid leukemia with double mutant CEBPA. Blood 2013;122:1576-82.

23. McNerney ME, Godley LA, Le Beau MM. Therapy-related myeloid neoplasms: when genetics and environment collide. Nat Rev Cancer 2017;17:513-27.

24. Takahashi K, Wang F, Kantarjian H, et al. Preleukaemic clonal haemopoiesis and risk of therapy-related myeloid neoplasms: a case-control study. Lancet Oncol 2017;18:100-11.

25. Gillis NK, Ball M, Zhang Q et al. Clonal haemopoiesis and therapy-related myeloid malignancies in elderly patients: a proof-of-concept, case-control study. Lancet Oncol 2017;18: $112-21$.

26. Godley LA, Larson RA. Therapy-related myeloid leukemia. Semin Oncol 2008;35:418-29.

27. Larson RA. Therapy-related myeloid neoplasms. Haematologica 2009;94:454-9.

28. Zuo Z, Medeiros LJ, Chen Z, et al. Acute myeloid leukemia (AML) with erythroid predominance exhibits clinical and molecular characteristics that differ from other types of AML. PLoS One 2012;7:e41485.

29. Ryu S, Park HS, Kim SM, et al. Shifting of erythroleukemia to myelodysplastic syndrome according to the revised WHO classification: biologic and cytogenetic features of shifted erythroleukemia. Leuk Res 2018;70:13-9.

30. Hasserjian RP, Zuo Z, Garcia C, et al. Acute erythroid leukemia: a reassessment using criteria refined in the 2008 WHO classification. Blood 2010;115:1985-92.

31. Pileri SA, Ascani S, Cox MC, et al. Myeloid sarcoma: clinicopathologic, phenotypic and cytogenetic analysis of 92 adult patients. Leukemia 2007;21:340-50.

32. Campidelli C, Agostinelli C, Stitson R, Pileri SA. Myeloid sarcoma: extramedullary manifestation of myeloid disorders. Am J Clin Pathol 2009;132:426-37.

33. Li Z, Stölzel F, Onel K, et al. Next-generation sequencing reveals clinically actionable molecular markers in myeloid sarcoma. Leukemia 2015;29:2113-6.

34. Fong CT, Brodeur GM. Down's syndrome and leukemia: epidemiology, genetics, cytogenetics and mechanisms of leukemogenesis. Cancer Genet Cytogenet 1987;28:55-76.

35. Webb D, Roberts I, Vyas P. Haematology of Down syndrome. Arch Dis Child Fetal Neonatal Ed 2007;92:F503-7.

36. Roy A, Roberts I, Vyas P. Biology and management of transient abnormal myelopoiesis (TAM) in children with Down syndrome. Semin Fetal Neonatal Med 2012;17:196-201.

37. Lange BJ, Kobrinsky N, Barnard DR, et al. Distinctive demography, biology, and outcome of acute myeloid leukemia and myelodysplastic syndrome in children with Down syndrome: Children's Cancer Group Studies 2861 and 2891. Blood 1998; 91:608-15.

38. Hitzler JK, Cheung J, Li Y, Scherer SW, Zipursky A. GATA1 mutations in transient leukemia and acute megakaryoblastic leukemia of Down syndrome. Blood 2003;101:4301-4.

39. Taub JW, Berman JN, Hitzler JK, et al. Improved outcomes for myeloid leukemia of Down syndrome: a report from the Children's Oncology Group AAML0431 trial. Blood 2017;129: 3304-13. 